\title{
'The voice of the street': Using peer led outreach with people who use drugs to inform the development of Ireland's National Drug Strategy
}

\author{
Brian Melaugh $^{1}$ and Hannah Rodrigues ${ }^{2}$
}

\begin{abstract}
The purpose of this article is to share how an Irish drugs advocacy organisation, UISCE conducted a consultation with 'People Who Use Drugs' (PWUD) to inform the development of Ireland's National Drugs Strategy: Reducing Harm Supporting Recovery. People who use drugs are considered a 'hard to reach' or 'hidden' population' who, because of their marginal status, are often absent from research and drug policy. Indeed, there is a lack of published data on how to engage with PWUD to inform policy development. The paper aims to extend the literature by highlighting how UISCE, employing a 'peer-led street outreach' approach, included 51 PWUD in the consultation to inform the Irish national drug strategy. Central to the paper is a description of the steps taken to conduct the consultation with a review of the challenges and benefits of using a 'street based recruitment' strategy to engage with hard to reach people who use drugs.
\end{abstract}

Keywords: hard to reach; people who use drugs; peer led; drug use; drug policy

1. Department of Applied Social Studies, National University of Ireland, Maynooth, Ireland

2. Coordinator, UISCE, Dublin, Ireland

Address for correspondence: brian.melaugh@nuim.ie

Date of first (online) publication: 2nd October 2018 


\section{Introduction}

Ireland adopted a national drug strategy approach to respond to the issues of drug and alcohol use in Irish society. As part of the development of that strategy, the Department of Health undertook a six week public consultation process commencing in September 2016. The purpose of the consultation was to ask the public for their views on the current strategy and gather feedback on what issues/areas should be considered in the new strategy. Irish drug policy accepts it is important to include the views of people who use drugs (PWUD) in the development of the national drugs strategy (Griffiths, et al, 2016). While this recognition is positive, there is an acceptance that people who use drugs, particularly those engaged in "high risk drug use' can be viewed as 'hard to reach' or 'hidden populations' (Dahlberg and Anderberg, 2013). Because of their marginal status the voice of PWUD is often absent from research and drug policy. Indeed, there is a lack of published data on how to engage with PWUD to inform policy development (Lianping, et al, 2012). The paper aims to develop the literature by describing how UISCE (an Irish representative group for People who Use Drugs) employing a 'peer led street outreach' approach successfully engaged with 51 PWUD to inform the development of the National Drugs Strategy. First, we set the paper in context by giving a history of UISCE, secondly the term 'hard to reach' is discussed and how the term relates to people who use drugs, thirdly, we explore the policy benefits from engagement with people who use drugs and finally we outline the process of the consultation itself.

\section{History and purpose of the Union for Improved Services Communication and Education for People Who Use Drugs (UISCE)}

Before discussing the emergence of the Union for Improved Services Communication and Education for People who Use Drugs (UISCE), it is important to address the issue of language and terminology used when writing about drug use. The article accepts the position adopted by the International Network of People who Use Drugs (INPUD) about the need to avoid terms such as 'drug user' or 'problem drug user'. These terms reduce the complexity of an individual's experience to the act of drug use and they have the potential to denigrate the individual so described (INPUD, 2011). In this article, we will only use terms such as 'drug user' when it is necessary to cite directly from sources using these terms. As INPUD recommends the use of the term 'People Who Use Drugs' (PWUD) and the specific term PWID for 'People Who Inject Drugs', we will use this terminology in the paper.

The origins of UISCE can be traced back to 1990 with the establishment of a 'self-directed support group for drug users' by the Ana Liffey Drug Project in Dublin (Bowden, 1997). The emergence of UISCE cannot be divorced from the wider drug use and drug policy environment of the time. Butler (1991), writing on the historical 
development of Irish drug policy, maintains the 1980s and early 1990s reflect a reluctant acceptance by the Irish State that Ireland (mainly Dublin) had a significant heroin issue. The acceptance of heroin was brought to the fore because of a concern about the risk of HIV transmission among PWID, through the practice of sharing needles. The emergence of UISCE was a response to the risks associated with the practice of 'injecting drugs'; from its early origins the organisation promoted 'harm reduction' and lobbied for services and strategies to reduce drug related harm. Indeed, Charlois (2009) describing the history of 'Drug User Organisations' refers to the 90 s as the 'HIV/AIDS Phase'.

In 1996 the 'First Report of the Ministerial Task Force on Measures to Reduce the Demand for Drugs' (Government of Ireland, 1996) accepted the link between social deprivation and problematic opiate use (Butler, 2007; O'Higgins, 1997). The report recommended the establishment of 'Local Drugs Task Forces' in areas identified as having the most acute drug problems. This included the North Inner City of Dublin with the establishment of a Local Drugs Task Force in 1997. This taskforce was one of the first to take active steps to support the representation of PWUD. It established 'user forums' which later adopted the name 'UISCE' (McAuliffe, 2007). The decision of the Task Force to fund UISCE was a key moment in the organisation's development, a decision that allowed for the employment of staff and the development of a work plan. In terms of structure, applying the classification of user organising developed by Charlois (2009), it represented the transition of UISCE from a 'forum' to a 'community based organisation'. While McAuliffe (2007) refers to the wider symbolic value of representation, the establishment and funding of UISCE conveyed a message to PWUD that they had a role to play in the decision making processes of the Task Force.

Today, the role of UISCE is to represent the voice of PWUD in the North Inner City of Dublin. The organisation is fully aware that change happens at both local and national levels, and from its early beginnings it accepted it had a role in supporting other local Drugs Task Forces to set up forums to represent PWUD, a role formally recognised by the Department of Health in its 2015 review of the National Drug Strategy 2008-2016 (Department of Health, 2015). Reviewing the progress of Action 42, with its focus on the development of 'Drug User Fora', it states: 'UISCE, a forum for Drug Users based in the North Inner City.....This organisation also assists Drug \& Alcohol Task Forces, who have set up a forum for drug users' (ibid, pp. 29-30). However, for representation to be genuine it needs to happen at all levels of the National Drugs Strategy. A concern for UISCE was that representation was primarily at local and regional levels. At national level, for example in the Office of the Minister for Drugs, there was no independent 'peer led' representation. In 2016, UISCE embarked on the development of a new strategic plan. The organisation was aware that the National Drugs Strategy (Interim) 2009-2016 was ending and of the need to influence the new strategy going forward. Strategic actions to influence the strategy included the request to be represented on the 'National Drugs Strategy 
Steering Committee' tasked with developing the new national strategy. In 2016 this request was approved and UISCE was appointed to the steering committee. In terms of representation UISCE wanted to ensure the voice of PWUD was included in the public consultation to inform the development of the strategy. Specifically the participation of people engaged in high risk drug use is a strategic priority for UISCE, a commitment grounded in the assessment that people who inject drugs constitute a hidden' or 'hard' to reach population (Dahlberg and Anderberg, 2013). In devising a consultation process, the organisation committed itself to a 'focus on people who have the least opportunity to have their voice heard. This means we actively seek out people who are currently injecting on the streets' (UISCE, 2016a, p. 3).

\section{Hard to reach people who use drugs}

People who use drugs are a diverse group with activity covering everything from recreational drug use to more problematic forms (Grosso and Gruppo, 2008). While accepting this reality the people who engage with UISCE share one common practice, the use of substances which are currently defined as 'illegal'. Criminalising drug use constructs it as a practice that is negative and indeed dangerous for both the user and society at large (Grosso and Gruppo, 2008; Gossop, 2000). From this perspective PWUD are constructed as 'criminals' and or 'addicts'. These stereotypes of drug use create a climate perfect for stigmatisation, marginalisation and indeed discrimination of PWUD. If drug use is associated with legal and moral sanction then PWUD will take steps to ensure their drug use remains hidden. In this context criminalisation and stigmatisation are barriers that prevent PWUD from engaging with health services and wider policy development fora, as such it constructs a population that is 'hard to reach'.

Criminalisation and stigmatisation of drug use have led to a situation where problematic drug use is to some extent hidden.... Some individuals are not interested in reporting their abuse to authorities because they are worried about negative consequences, and others with problematic drug use have no contact whatsoever with the social or health care system' (Dahlberg and Anderberg, 2013, p. 149).

Research by Corr (2002) into the efficacy of outreach approaches to engage with hard to reach PWUD in Dublin highlights how psychological, organisational and geographical factors act as barriers to engagement. While the research is focused on service delivery these factors are also identified as barriers in conducting research and policy development with hard to reach populations (Shaghaghi, et al, 2011) and specifically with PWUD (Lianping, et al, 2012).

At a personal level PWUD may fear the consequences of contact with services e.g. parents with children may conceal their drug use because of concerns about social 
service intervention. At an organisational or agency level drug using behaviour may lead to exclusion from services. At a geographical level, drug use, particularly that which involves people who inject drugs (PWID), may take place on the 'street' or hidden locations, such as 'alleyways', which are difficult to access. PWID are described in the literature as 'the most discriminated against, marginalised, criminalised and experiencing some of the most serious health problems' (INPUD, 2011, p. 3). As a group they are invariably young, male, often homeless and engage in drug use defined as high risk i.e. the regular use of opioids, cocaine and amphetamines (EMCDDA, 2017). In Ireland, it is estimated that over 13,458 people in Dublin meet the criteria for 'high risk drug use' (Bates, 2017). However, research evidence suggests that around 9,900 of this number enrolled with treatment services in 2016 (EMCDDA, 2017). It can be deduced that around 3,500 PWUD are particularly marginalised, reflecting the characteristics associated with hard to reach populations.

\section{Engagement with people who use drugs}

Hunt (2002) highlights the value for policy and service development of engaging with 'hard to reach' people who use drugs. For Hunt the 'drug scene' is subject to ongoing change, at local and national levels, for example emergence of new drugs and local sites where people use drugs are open to change. This knowledge is hidden from professionals and getting access ensures policy and services are relevant and responsive to the needs of PWUD:

Professionals undoubtedly have important expertise, but much valuable knowledge for understanding how services can best be organised and delivered -what might work in a given locality and identifying emerging needs-is possessed by drug users not professionals (Hunt, 2002, p. 16).

In regards to engagement Hunt highlights the distinction between 'involvement' and 'empowerment'. Involvement denotes some participation, usually at the level of service provision, for example 'service user feedback'. Empowerment is much wider, with a focus on policy change and reflects a motivation that PWUD should be supported to identify the issues that impact on their lives and also play an active part in addressing these concerns. Empowerment reflects the thinking of community development (Ledwith, 2011) and indeed is reflective of the approach that guides the work of UISCE.

UISCE was committed to engaging with PWUD 'injecting on the street', to ensure their views were included in the consultation on the development of the national drugs strategy. This commitment presented the organisation with a number challenges: how to get access to this community, ethical issues of safety and consent and the logistical demands of conducting the consultation in the time allocated. 
As discussed, there is a lack of research evidence on how to engage with hard to reach PWUD (Lianping, et al, 2012). However, when engagement is successful the literature highlights the importance of using 'peer-led' and outreach approaches to inform policy development (Corr, 2002; Jürgens, 2008; Kerr, et al, 2006: Lianping, et al, 2012).

\section{Carrying out a consultation to inform the National Drugs Strategy}

The use of peer led outreach is integral to the practice of UISCE and, therefore, it made sense to employ this approach in the consultation process. Outreach can be defined as engaging with people at the front line of drug services with a commitment to identify and contact hidden populations (Corr, 2002; EMCDDA, 2001). 'Peer led outreach' is carried out by PWUD using their knowledge and contacts to engage with members of their own community (Grosso and Gruppo, 2008). To conduct the consultation UISCE divided the process into four phases: planning, implementation, collation, analysis and dissemination of findings. Rather than reviewing each stage separately we will focus on the overall learning by exploring the challenges (and indeed the opportunities) the consultation presented and evaluate the role played by peer led outreach. We will also present some of the key findings and recommendations to emerge from the consultation.

To conduct a consultation with 'hard to reach' PWUD it is essential to consider how you are going to contact participants, what method/s will be employed to collect the information and how to respond to ethical concerns of informed consent, confidentiality and safety. To some degree a number of these considerations were decided in advance. UISCE employs a peer led approach to inform its work and has established protocols for the induction and training of peer outreach volunteers. As UISCE was participating in a public consultation it technically was not conducting research and therefore it was not necessary to apply for ethical approval. As an organisation we comply with ethical frameworks which guide engagement with PWUD, namely the Vancouver Declaration (IAUD, 2006) and 'Nothing about Us without Us Consulting with people who use drugs: Do's and don'ts' (Jürgens, 2008). Adherence to these frameworks demands that UISCE respects people's right to engage and takes every step to protect their privacy and confidentiality. The method adopted by the National Drugs Strategy Steering Committee to inform the public consultation was a questionnaire covering key areas from supply reduction to research. The questionnaire was piloted with UISCE volunteers and based on their feedback UISCE adapted the questionnaire. From the volunteer's perspective the questionnaire was difficult to understand and the wording was not fully accessible for people who use drugs (UISCE, 2016b). To support engagement UISCE consulted 
with the community to rewrite the questionnaire, retaining the core emphasis of the questions but ensuring the language used was easy to comprehend. To support the consultation the adapted questionnaire was discussed with volunteers to ensure they understood the questions and were confident to respond to requests for clarification.

The most challenging part of the consultation was the element of street based recruitment. In summary, this included getting access to PWUD and gaining their consent to complete the questionnaire. Regarding the practice of peer-led approaches Grosso and Gruppo (2008) refer to the 'initiative group' who wants to get access to PWUD and the 'peer operator' who makes this access happen. In the context of the consultation reported here, UISCE was the 'initiative group' using the expertise of peers to act as gatekeepers to access the hard to reach PWUD. Therefore, the quality of access was dependent on how well the peers were known to PWUD congregating on the street. If the peer was known to a group, or was welcomed into the group, meaningful engagement was possible. Indeed there was an opportunity to use the sample technique of 'snowballing' by asking each participant to nominate someone else to complete the questionnaire (Shaghaghi, et al, 2011). The challenge is when people are not in public view (e.g. beside drug services) but are actively avoiding areas because of concerns about police, or drug debt. In these situations the group may be 'suspicious' and any decision about engagement needs to ensure the safety of both the peers and participants.

A practical challenge was the weather with the consultation taking place in October. As each questionnaire took around forty minutes to an hour to complete, when it was wet and cold, it was often necessary to retreat indoors (coffee shop). Occasionally people requested to go to a drug agency to complete the questionnaire. However, an unexpected challenge was concern from agencies about completing questionnaires on their premises. We accept that this may be a matter of communication. However, a number of peers were known to the agencies as 'service users' and it may also be linked to a change in the peer's relationship with the agency, a dual role of user and representative. Despite the challenges UISCE successfully completed 51 questionnaires. The experience of conducting the consultation reflects Abrams' (2010) assessment of the use of 'street based recruitment approaches'. The main strength is exposure to the most at risk individuals and groups, while the weakness includes the time it takes to locate and select participants.

For Hunt (2002) a characteristic of empowerment is the involvement of PWUD as decision makers in all parts of the process. When planning the consultation we wanted to include the peers in the process of analysing the data from the questionnaires. However, the goal was to ensure that the voices of PWUD on the streets of Dublin were included in the consultation. As the consultation period was short (six weeks) we took the pragmatic decision for a staff member to collate, analyse and write a submission. Before the submission was finalised it was shared with the peers who conducted the consultation. The final submission 'Your Voice -2017 National Drugs Strategy' was shared widely among PWUD. In December 2016, a complete copy of 
the submission was included in a special edition of the UISCE magazine, the 'Brass Munkie' (UISCE, 2016b). The magazine was disseminated widely with over 1000 copies distributed to individuals and services through outreach.

In terms of an overview of the 51 people who participated in the consultation, $88 \%$ were male and $11 \%$ were female. As age was not a category in the questionnaire we did not record the age of participants. In terms of choosing a category to define oneself the questionnaire offered a number of categories including: individual, service user, professional. While a number of participants selected more than one option, the majority (80\%) defined themselves as 'service users'. This is interesting as it may challenge our understanding of 'hard to reach' as 'service user' denotes engagement with a service. A limitation of using a set questionnaire was the inability to ask participants to elaborate on their answers. Regarding drug use, $78 \%$ maintained it was easy to access 'illicit drugs' in Ireland, while $72 \%$ identified heroin, followed by prescription (excluding methadone) medication (47\%), as the most harmful drugs. In terms of managing the harm associated with drug use, $72 \%$ maintained they were informed about the dangers of drug misuse, with information on drugs coming mainly through peer networks. Drug treatment emerged as the most pressing concern with $60 \%$ of participants agreeing that it was difficult to access treatment in a timely fashion that was appropriate to their needs.

When asked about the existence of the National Drugs Strategy (2008-2016) $68 \%$ of participants were not aware of its existence. This level of awareness is higher than the total sample of participants who submitted their views to the consultation, with 73\% indicating they were not aware of the National Drugs Strategy (RPA Consulting, 2017). This rate of lack of awareness is a concern as a drugs strategy has real implications for people who use drugs. Indeed, Hunt, et al (2010), citing Friedman (1996, p. 212), highlight how 'the structure of the drug scene affect what users' groups can do and how they function'. Drug strategies play a major role in the construction of a drug scene from access to treatment to the construction of drug use as a health or justice issue. To balance the strategy towards a more holistic health focused approach UISCE's main recommendation was for the inclusion of people who use drugs in the structures responsible for its implementation:

UISCE recommends the inclusion of people who use drugs and services in the development of the 2017 strategy. UISCE recommends a strategic communication plan be developed for the strategy which includes people who use drugs and services. Before designing any new services UISCE recommends seeking feedback from people who use drugs in the immediate geographical area and developing unique services based on this information (RPA Consulting, 2017, p. 28).

While it is too early to evaluate the impact of Ireland's National Drug Strategy, 'Reducing Harm, Supporting Recovery' (Department of Health, 2017), from the perspective of including people who use drugs there are some interesting developments. UISCE was appointed to the 'National Oversight Committee' which has the role of 'giving leadership and direction to support the implementation of 
the strategy' (Department of Health, 2017, p. 76).

In conclusion, the exercise of conducting a consultation with 'hard to reach' people who use drugs to inform Ireland's National Drug Strategy highlights the value of using peer led approaches to engage with hidden populations. The challenge is that a 'street recruitment' approach is resource intensive and demands the careful management of safety concerns for peers and participants. Including the voice of people who use drugs in the development of the National Drugs Strategy in Ireland was paramount for UISCE. However, the questionnaire format used meant it was not possible to explore responses in depth. To inform its capacity to represent on the National Drugs Strategy, UISCE intends to explore the feasibility of conducting a peer-led research study to better understand the experience of hard to reach people who use drugs in Ireland.

\section{References}

Abrams, L. (2010) Sampling 'Hard to Reach' Populations in Qualitative Research: The Case of Incarcerated Youth. Qualitative Social Work, 9, 536-550.

Bates, G. (2017) The drugs situation in Ireland: an overview of trends from 2005 to 2015. Liverpool: Centre for Public Health at Liverpool John Moores University.

Bowden, M. (1997) Ana Liffey Drug Project: A Report on the First Fifteen Years.Dublin: Ana Liffey Drug Project.

Butler, S. (1991) Drug problems and drug policies in Ireland: A quarter of a century reviewed. Administration, 39, 3, 210-233.

Butler, S. (2007) Rabbitte revisited: the First Report of the Ministerial Task Force on Measures to Reduce Demand for Drugs -ten years on. Administration, 55, 3, 125-144.

Charlois, T. (2009) Drug user participation and European cities. Strasbourg: EXASS.

Corr, C. (2002) Engaging the Hard to Reach: An Evaluation of an Outreach Service. Dublin: Merchants Quay Ireland.

Dahlberg, M. and M. Anderberg. (2013) The hidden population: Some methodological issues about estimation of problematic drug use. Nordic Studies on Alcohol and Drugs, 30, 3,149-166.

Department of Health (2015) National Drugs Strategy 2009-2016: progress report to end 2014. Dublin: Department of Health.

Department of Health (2017) Reducing Harm,Supporting Recovery A health-led response to drug and alcohol use in Ireland 2017-2025. Dublin: Department of Health.

European Monitoring Centre for Drugs and Drug Addiction (EMCDDA) (2001) Guidelines for the Evaluation of Outreach Work. Luxemboug: EMCDDA.

European Monitoring Centre for Drugs and Drug Addiction (EMCDDA) (2017) Ireland Country Drug Report 2017. Luxembourg: EMCDDA.

Friedman, S. (1996) Theoretical bases for understanding drugs users' organizations. 
International Journal of Drug Policy, 7, 212-219.

Gossop, M. (2000) Living with Drugs. Aldershot: Ashgate.

Government of Ireland (1996) First Report of the Ministerial Task Force on Measures to Reduce the Demand for Drugs. Dublin: Government of Ireland.

Griffiths, P., Strang, J. and Singleton, N. (2016). Rapid expert review of the National Drugs Strategy 2009-2016 Dublin: Department of Health [Accessed 10 January 2018 at http:// www.drugsandalcohol.ie/27289/]

Grosso, L. and Gruppo, A. (2008) Empowerment - Models of good practice: Heroin use and peer support What lessons have been learnt? In G. Bröring and E. Schatz(Eds.) Empowerment and Self: Organisations of drug users experiences and lessons learnt. Amsterdam: Foundation Regenboog AMOC Correlation Network (pp. 41-57).

Hunt, N. (2002) Involvement and Empowerment Why Bother? Drug Link, Jan/Feb.

Hunt, N., Albert, E. and Sánchez, V. (2010) User Involvement and user organising. In T. Rhodes and D. Hedrich (Eds. ) Harm reduction: Evidence, impacts and challenges. Luxembourg: European Monitoring Centre for Drugs and Drug Addiction (EMCDDA) (pp. 333-357).

IAUD (2006) Vancouver Declaration: Why the world needs an international network of activists who use drugs. Vancouver Canada: The International Activists who use Drugs.

INPUD (2011) Statement and Position Paper On Language, Identity, Inclusivity and Discrimination. London: INPUD (International Network of People who Use Drugs).

Jürgens, R. (2008) Nothing about us without us - Greater, meaningful involvement of people who use illegal drugs: A public health, ethical, and human rights imperative, International edition. Toronto: Canadian HIV/AIDS Legal Network, International HIV/AIDS Alliance, Open Society Institute.

Kerr, T., Small, W., Peeace, W., Douglas, D., Pierre, A. and Wood, E. (2006) Harm reduction by a 'user-run' organization: A case study of the Vancouver Area Network of Drug Users (VANDU). International Journal of Drug Policy, 17, 2, 61-69.

Ledwith, M. (2011) Community Development: A critical approach. Bristol: Policy Press.

Lianping, T., Tzemis, D. and Buxton, J. (2012) Engaging people who use drugs in policy and program development: a review of the literature Substance abuse treatment, prevention, and policy, 7, 1, 47-47.

McAuliffe, R. (2007) The Work of UISCE. In J, Bennett (Ed.) Developing Drug and Service User Forums Conference Report. Dublin: Finglas/Cabra Local Drugs Task Force.

O' Higgins, K. (1997) Review of Literature and on policy on the links between Drug Use and Poverty. Dublin: Combat Poverty Agency.

RPA Consulting (2017) Report on Public Consultation undertaken to inform the new National Drugs Strategy. Dublin: Department of Health.

Shaghaghi, A.R.S., Bhopal, R.S. and Sheikh, A. (2011) Approaches to Recruiting 'Hard-ToReach' Populations into Research: A Review of the Literature. Health Promotion Perspectives, $1,2,86-94$.

UISCE (2016a) UISCE Strategic Plan 2017. Dublin: Union for Improved Services Communication and Education 